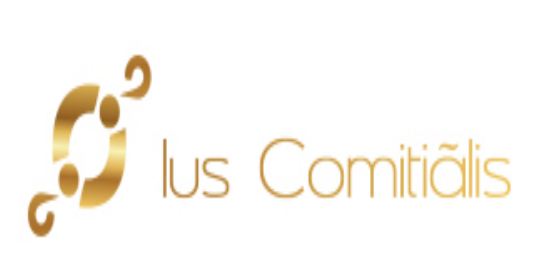

Ius Comitiãlis

ISSN: 2594-1356

iuscomitialis@uaemex.mx

Universidad Autónoma del Estado de México

México

Gutiérrez López, Eduardo Elías

Principales enfoques analíticos de los derechos humanos: una revisión a su pertinencia metodológica

Ius Comitiãlis, vol. 3, núm. 5, 2020, Enero-Junio, pp. 115-130

Universidad Autónoma del Estado de México

México

DOI: https://doi.org/10.36677/iuscomitialis.v3i5.13654

\title{
Número completo
}

Más información del artículo

Página de la revista en redalyc.org 


\title{
Principales enfoques analíticos de los derechos humanos: una revisión a su pertinencia metodológica \\ Main analytical approaches to human rights: a review of their methodological relevance
}

\author{
Eduardo Elías Gutiérrez López*
}

\section{(c) $(1)(9)$}

Esta obra está bajo licencia Creative Commons Attribution-NonCommercial-ShareAlike $\quad 4.0$ International (CC BY-NC-SA 4.0)
Resumen La discusión de los derechos humanos se ha centrado en presupuestos teóricos y génesis conceptual, y se ha dejado de lado su apartado metodológico: aquellos procesos para que el estudio de los derechos humanos trascienda de la reflexión teórica y el reconocimiento legislativo, a la realidad social, al modo en que estas prerrogativas operan al entrar en el mundo de las relaciones sociales. Se pretende generar un diálogo crítico entre los principales enfoques sobre los derechos humanos para sugerir una metodología enfatizada en el sujeto titular de los derechos y no en el Estado, como hegemónicamente se efectúa en la academia.

Palabras clave Derechos humanos, enfoques analíticos, metodología, sociología, relaciones sociales.

Abstract The discussion of human rights has focused on theoretical assumptions and conceptual genesis and its methodological section has been left aside: those processes so that the study of human rights transcends from theoretical reflection and legislative recognition to social reality, the way in which these prerogatives operate when entering the world of social relations. The aim is to generate a critical dialogue between the main approaches to human rights, to suggest a methodology emphasized in the subject of rights and not in the State, as it is hegemonically carried out in academia.

Key words Human rights, analytical approaches, methodology, sociology, social relations.

*Doctor en Estudios de Migración y Maestro en Ciencias Jurídicas. Profesor de Tiempo Completo de la Facultad de Derecho Tijuana de la Universidad Autónoma de Baja California, México. Presidente de la Academia de Filosofía del Derecho de la Universidad Autónoma de Baja California.

ORCID: orcid.org/0000-0002-9171-8813.Correo electrónico: elias.gutierrez@uabc.edu.mx 


\section{INTRODUCCIÓN}

Los derechos humanos como enfoque teórico han sido abordados desde diversas disciplinas (Derecho, Ciencia Política, Sociología, Antropología, Relaciones Internacionales, etc.). Por lo que, contrario a lo que se podría anticipar, la ciencia jurídica no ha tenido el monopolio -aunque sí la hegemonía- de su estudio y discusión. Sin embargo, ha sido a través de este ejercicio multidisciplinario como se ha podido reflexionar en torno a las diversas facetas que tienen los derechos humanos (Estévez, 2017, pp. 370-376) y se ha conseguido una aproximación más crítica de sus concepciones teóricas.

Los procesos de globalización en el mundo y la llamada "transición democrática" complejizaron el discurso e interpretación de los derechos humanos. En consecuencia, se experimentó una disminución en el rol hegemónico del Derecho para su constitución y legitimación teoréticas (Arias, 2011, p. 23). Esta complejidad trajo como respuesta la integración de otras disciplinas al estudio de los derechos humanos y un intento por propiciar un análisis de carácter integral, así como por definir la relación que guardan estas prerrogativas humanas con distintos fenómenos políticos, sociales y culturales.

Empero, aunque se ha experimentado un incremento en el número de campos disciplinares que se ocupan de los derechos humanos, el enfoque dominante sigue siendo el mismo: una posición estado-céntrica, es decir, "centrada en el Estado y además inscripta en un sistema estatal" (García, 2016, p. 125). Esta posición estado-céntrica se ve reflejada en el hecho de que gran parte de los trabajos o estudios acerca de los derechos humanos tienen su principal énfasis en el papel asumido por los Estados, en las actuaciones de las diferentes autoridades o en el marco legislativo interno o internacional que versa en torno a estas prerrogativas. Las implicaciones de una visión estado-céntrica conllevan a la confección de un enfoque analítico en el que predomine la preocupación por las instituciones gubernamentales y no por las personas titulares de los derechos.

Este trabajo tiene como primer objetivo revisar los enfoques analíticos de los derechos humanos (enfoque filosófico, enfoque jurídico político y enfoque sociológico) que mayor presencia han tenido en las investigaciones de las Ciencias Jurídicas y Sociales (aunque no se duda que existan otros) y hacer un recuento de sus características y debilidades. Así mismo y como segundo objetivo, se subraya una metodología que permita encausar el énfasis de las investigaciones -sociales y jurídicas- en materia de derechos humanos al sujeto titular y no necesariamente al Estado o a los organismos delegados para la protección, promoción y defensa de estas prerrogativas, y a los marcos legislativos internos e internacionales, a afecto de recabar información y datos de un modo más integral y directo. 


\section{ENFOQUES ANALÍTICOS DE LOS DERECHOS HUMANOS}

Como se ha advertido en la introducción de este trabajo, la hegemonía respecto al análisis de los derechos humanos la ha sostenido la Ciencia Jurídica, por tanto, no es inusual que cuando se realice un estado del arte acerca de los presupuestos teóricos de los derechos humanos, sean los estudios jurídico-normativos los que predominen y las aulas de estudiantes de las Ciencias Jurídicas, donde más se hable de derechos humanos, ya sea desde el punto interno o constitucional, o bien, desde el externo o internacional. Empero, como todo tópico a reflexionar requiere de una justificación teórica, el Derecho ha tenido que recurrir a la Filosofía y a la Sociología para contar con un basamento que robustezca sus extensos avances legislativos y legitime su discurso político contemporáneo.

Desde otra trinchera se comenzó a construir otra visión de los derechos humanos y ello, en gran medida, obedeció al interés de algunas Ciencias Sociales (Sociología, Antropología, Ciencia Política, etc.) por indagar en este tema. El estudio de diferentes fenómenos sociales, políticos y culturales, que son objetos de estudio de estas disciplinas, tarde que temprano, les fue llevando hacia los derechos humanos como una vía para observar y entender dichas abstracciones de la realidad, y entonces, se constituyeron otros enfoques, distintos a la óptica jurídica y se generó un andamiaje interdisciplinario para abordar todas estas cuestiones.

Por ejemplo, para Arias (2015, pp. 15-16) existen cuatro grandes escuelas en la producción teórica y académica de los derechos humanos: a) la naturalista, que considera a los derechos humanos naturales y universales en tanto que son parte de la estructura misma del universo, b) la deliberativa, que estima a los derechos humanos como resultados de la construcción de consensos sobre cómo la política de la sociedad debe de ser orientada, $y$, por tanto, la universalidad depende de que tanta capacidad se tenga para ampliar el consenso acerca de estas prerrogativas, c) la de resistencia o protesta, que concibe a los derechos humanos como producto de las luchas sociales, y aunque los contempla como universales, su universalidad radica en la globalización del sufrimiento y del rol universal de víctima, y, d) la discursiva, que prevé que el fundamento mismo de los derechos humanos no es otro sino un hecho de lenguaje.

Para los propósitos y extensión de este trabajo, se ha considerado analizar los tres enfoques analíticos de los derechos humanos que se estiman más determinantes en las Ciencias Sociales y Jurídicas, sin que, como ya se ha dicho, quiera decir que no existan otros igual o más importantes en virtud del carácter multi o interdisciplinario de los derechos humanos.

\section{ENFOQUE FILOSÓFICO DE LOS DERECHOS HUMANOS}

Las primeras nociones de los derechos humanos se inscribían dentro de una visión filosófica, sobre todo delineando una conexión necesaria con la naturaleza humana (Bidart, 1989, pp. 13-17). De allí que se haya seguido de forma preponderante una noción de los derechos humanos -que en algunos círculos persiste hasta la fecha- que les concibe como elementos congénitos a la persona, es decir, como un conjunto de atributos connaturales a la especie humana, producto de su dignidad y que en ningún caso son -o podrían ser- interpretados cual "una concesión de la 
sociedad política" (Truyol, 1968, p. 11 en Bidart, 1989, p. 16), pues se consideran anteriores a la conformación del Estado.

Esta idea ha conservado vigencia y ha sido secundada por las narrativas adoptadas por los instrumentos jurídicos internacionales sobre derechos humanos, así como por los principios en los que se han depositado sus características. Esta idea se ve matizada de forma ilustrativa en la Declaración Universal de los Derechos Humanos (DUDH) de 1948, instrumento que además de representar un ideal para todos los pueblos, fue un punto de inflexión en el tema de derechos humanos a partir de la conclusión de la Segunda Guerra Mundial y la creación de la Organización de las Naciones Unidas (ONU). En este instrumento legal se adopta la reflexión de que "todos los seres humanos nacen libres e iguales en dignidad y derechos" (DUDH, 1948, ARTí́CULO 1º).

Esta naturaleza humana que se aborda en esta percepción filosófica y que es rescatada por la DUDH, tiene como ingredientes fundamentales la universalidad, la igualdad y la objetividad. Estos ingredientes se basan en la dignidad intrínseca de las personas y sostienen que los derechos humanos son para todos y que existen, aunque no se reconozcan o no se quieran reconocer (Velásquez, 2013, p. 759).

Sin embargo, admitir totalmente la pertinencia de este enfoque de los derechos humanos conduciría el debate hacia la omisión de tres aspectos centrales de la discusión. En primer término, se dejaría de lado la aceptación de que existen países en donde no se tienen por reconocidos estos derechos universalmente "consensados" y que, por lo tanto, la articulación sobre sus fundamentos, naturaleza y principios -aunque necesaria- no dirime un conflicto sobre violación o irrespeto. Pues de poco sirve a una persona saberse poseedor "natural" de una gama de derechos, si finalmente no puede ejercerlos bajo condiciones óptimas. Estas condiciones sólo pueden constituirse en la medida en que, como primer paso, los derechos humanos se institucionalicen, aunque, también la evidencia histórica ha comprobado que los derechos institucionalizados no necesariamente guardan relación con su goce y disfrute.

Por ejemplo, para Rubalcava (2014, pp. 48-49), una investigación sobre derechos humanos tiene dos enfoques de atención; uno recae sobre el sujeto obligado y otro sobre el sujeto pretensor o titular. Por lo que existe una conexión necesaria entre el cumplimiento del Estado obligado y el goce por parte del sujeto o de la colectividad titular, por consiguiente, no debe considerarse satisfecho si no existe una garantía para el ejercicio pleno de ese derecho (Rubalcava, 2014, pp. 48-49).

Esta omisión de reconocimiento de algunos derechos humanos puede darse por decisión propia de los Estados en el uso estricto de su soberanía o bien, por lo que algunos autores han denominado multiculturalismo.

Este multiculturalismo comprendido como un fenómeno inherente a algunas sociedades contemporáneas, en el que, fenómenos como la religión y los crecientes flujos migratorios desarrollan cambios holísticos que repercuten en el área de los derechos humanos. Es por ello, por lo que, con base principalmente en factores culturales, algunos derechos humanos no son reconocidos o regulados de la misma manera en diferentes países o inclusive son omitidos por completo.

En segundo término, vale la pena aludir a la diferencia que algunos autores encuentran entre los derechos humanos y los derechos fundamentales. Por ejemplo, para Carpizo (2011, p. 14), mientras que los derechos humanos no necesariamente han sido objeto de recepción por los sistemas jurídicos, los derechos fundamentales son aquellos que ya han sido reconocidos y garantizados por los Estados en sus constituciones y, según sea el caso, por el Derecho Internacional de los Derechos Hu- 
manos. De manera que, si se siguiera esta lógica, el punto central de los derechos humanos no radicaría en su naturaleza o en la dignidad intrínseca de las personas, sino en los procesos de fundamentalización a través de los cuales estos derechos dimanados de la naturaleza humana han sido recibidos, regulados y garantizados por el derecho interno y/o por el derecho internacional.

En tercer término, existe una visión analítica de los derechos humanos que para nada los considera elementos inherentes a la naturaleza humana, a esta escuela de los derechos humanos, Arias (2015, pp. 15-16) la ha denominado de protesta o de resistencia y concibe a estas prerrogativas como producto de las luchas o movimientos sociales y no como cualidades consustanciales a una supuesta naturaleza humana. Un ejemplo ilustrativo de este enfoque analítico fue la lucha por los derechos civiles de personas afrodescendientes en Estados Unidos y su repertorio de acciones colectivas, tales como protestas, manifestaciones y formación de organizaciones, pues se constituyó como un movimiento social que a la postre terminaría por incidir en la reconfiguración de la noción -hasta ese entonces conocida- de los derechos humanos.

Bajo esa tesitura, el enfoque filosófico de los derechos humanos basado en una teoría general que aluda a su naturaleza, fundamentación y génesis -reconociendo su trascendencia e imprescindibilidad-no alcanza a responder a los factores que producen violaciones aisladas o sistemáticas de derechos humanos. Para poder acceder a las respuestas de estos planteamientos, no bastaría con responder a los criterios filosóficos o hermenéuticos que componen este enfoque, sino que habría que adentrarse al campo de la realidad, de la práctica y de la eficacia de estos derechos en la esfera de acción de los sujetos titulares y en las diversas relaciones sociales que son resultado de los derechos humanos.

ENFOQUE JURÍDICO-POLÍTICO DE LOS DERECHOS HUMANOS

Un segundo enfoque se basa precisamente en el proceso de fundamentalización de los derechos humanos. El proceso puede o debe darse a través de dos ejercicios soberanos: el constitucional y el internacional. Los Estados por lo general establecen en sus Constituciones: 1) un catálogo de derechos humanos, 2) las condiciones en que estos habrán de desarrollarse y 3) las garantías o mecanismos de protección con que cuentan los individuos titulares; este sería el ejercicio soberano constitucional. Posteriormente, algunos Estados deciden o no, adherirse o suscribir acuerdos internacionales sobre derechos humanos en los que el catálogo puede ampliarse o consolidarse e inclusive pueden aceptar jurisdicción contenciosa para que órganos supranacionales puedan intervenir en casos de violaciones a derechos humanos, en uso del ejercicio soberano internacional. En el caso de la Corte Interamericana de Derechos Humanos, que es el tribunal para los Estados Americanos que han aceptado jurisdicción supranacional; ésta se despliega en cuatro vertientes jurisdiccionales: la consultiva, la contenciosa, la preventiva y la ejecutiva (García Ramírez, 2008, p. 188).

Este enfoque de los derechos humanos ha sido robustecido por el Derecho Constitucional y por el Derecho Internacional de los Derechos Humanos. El Derecho Internacional de los Derechos Humanos comprende el sistema universal y los regionales de derechos humanos, dentro de los que los Estados buscan la mejor protección de quienes se encuentren bajo su jurisdicción, ya sea con el reconocimiento de ciertos derechos o bien con la creación de garantías procesales que 
subsanen lo que el orden jurídico interno no haya podido defender a través de sus recursos (Carpizo, 2012, p. 803).

Actualmente existen tres sistemas regionales de derechos humanos, además del universal que tiene a la ONU como actor principal. Estos son: el africano que tiene como órgano matriz a la Unión Africana, el europeo que tiene como eje rector al Consejo Europeo y el interamericano que tiene como órgano toral a la Organización de los Estados Americanos. Estos sistemas pretenden proteger los derechos de los individuos en los casos en que el derecho interno no lo haya hecho (Heyns, Padilla y Zwaak, 2006, p. 165).

Es por ello, por lo que la Ciencia Política y las Relaciones Internacionales han comenzado a tener un papel primordial en el estudio de los derechos humanos. Pues a través de la coordinación de distintos Estados se han construido acuerdos multilaterales que tienen como finalidad la protección de estas prerrogativas. En consecuencia, ha perdido protagonismo la naturaleza como aspecto toral de los derechos humanos, ya que el efecto esperado en su tutela y comprensión nace a partir de la voluntad de los Estados por diseñar un aparato estructural de estos derechos en sus Constituciones, o bien, por consentir con otros Estados en la consolidación de un sistema internacional o regional para su garantía.

$\mathrm{Al}$ igual que en el enfoque basado en la naturaleza de los derechos humanos, existen algunas dimensiones que requieren ser analizadas. En un momento histórico-social en el que los derechos humanos se han transformado en un discurso sumamente politizado, los intereses de los Estados por considerarles se han vuelto más consistentes. Con base en este juicio, se torna necesario estudiar cuáles son las verdaderas razones tras las intenciones de los Estados por suscribir un tratado internacional o fortalecer sus mecanismos de tutela de los derechos humanos. Este tópico no es objetivo de este trabajo, sin embargo, a continuación, se muestran los resultados de algunos estudios al respecto.

Algunos autores (Flores-Ivich y Salazar-Elena, 2014; Goodman y Jinks, 2004 en Flores-Ivich y Salazar-Elena, 2014; Simmons, 2009 en Flores-Ivich y Salazar-Elena, 2014) han expuesto que, en ocasiones, las motivaciones que encaminan a los Estados (o a los dirigentes de los gobiernos y los partidos preponderantes) a formar parte de un instrumento jurídico internacional, se traducen en una imitación de conductas deseables o una paradoja de promesas vacías. De allí que, de acuerdo con su postura, éstas puedan clasificarse en cínicas y sinceras. En otras palabras, la signatura de un tratado internacional no produce en automático una mejora en la protección de los derechos humanos, salvo que la pretensión de fondo sea realmente ésta y no fortalecer vínculos comerciales, relaciones interestatales o simplemente presentar un rostro afable como Estado a la comunidad internacional.

Una crítica hacia este tipo de perspectivas que se basan en la institucionalización internacional de los derechos humanos es que la adhesión y ratificación de estos instrumentos no necesariamente implican una mejora para los países firmantes, lo que sin duda obedece a la falsa voluntad del Estado al adscribirse a los ordenamientos internacionales o a los sistemas regionales de protección de derechos humanos. Otra crítica subraya el poco interés de algunos Estados por ratificar los instrumentos jurídicos internacionales cuando estos puedan afectar posturas políticas internas. Un caso ilustrativo de esta segunda crítica se manifiesta en el tema de la migración internacional, pues a pesar de la existencia de la Convención Internacional sobre la protección de los Derechos de todos los Trabajadores Migratorios y sus Familiares, adoptada en la Asamblea General de la ONU el 18 de diciembre 
de 1990, a la fecha sólo ha sido ratificada por 42 países, ninguno de los cuales es considerado un destino de migrantes (CELADE y CEPAL, 2010).

Este ejemplo muestra cómo los procesos de fundamentalización de los derechos humanos a través de fuentes de carácter internacional, corren el riesgo de convertirse en actos manejables por los Estados que, en la mayoría de los casos, los ejecutan sólo mediante intereses políticos y económicos y no de protección de los derechos humanos.

En síntesis, comprender a los derechos humanos a partir de un enfoque internacionalista o constitucionalista, es decir, a través de los instrumentos que les institucionalizan, es un ejercicio que únicamente alcanza uno de los dos flancos que les componen, ya que el rol de los Estados para la construcción y organización de su orden interno y la capacidad para relacionarse con otros Estados es una parte importante, pero no la única desde la que pueden abordarse. No debe dejarse de lado la intervención del sujeto titular de estos derechos; aquel que frente al Estado tiene la potestad de demandar su cumplimiento por conducto de las garantías que hayan sido, interna e internacionalmente diseñadas.

\section{ENFOQUE SOCIOLÓGICO DE LOS DERECHOS HUMANOS}

Tomando en consideración que el abordaje que proporcionan los enfoques analíticos anteriores no convenció teóricamente a muchas de las Ciencias Sociales y a un segmento crítico de las Jurídicas, se comenzó a edificar otra óptica de los derechos humanos, una de contrastes, de facetas. Estévez (2017, p. 367) lo explica muy bien en la siguiente reflexión:

Los derechos humanos, cuenta la leyenda, son los derechos que tenemos todos los seres humanos por el simple hecho de ser humanos. Sin embargo, como se observa en la cotidianidad mundial, esto no es cierto. A pesar de que la vida, la integridad física, el empleo, la vida libre de explotación y de violencia, y la protección internacional frente a la persecución son derechos humanos reconocidos mundialmente, cada día miles de personas son heridas o asesinadas a manos de militares, terroristas, guerrilleros, corporaciones o algún familiar. Millones se encuentran sin empleo o en condiciones análogas a la esclavitud, el medio ambiente no es propicio para la vida en diversos territorios, y las grandes potencias económicas y militares invaden y matan a nombre de los derechos humanos.

Esta clase de reflexiones causaron que desde la Sociología comenzará a nacer un interés por el estudio de los derechos humanos, desde la postura de concebir a estos, no solamente como normas jurídicas sino como fenómenos sociales, es decir, a partir de la Sociología Jurídica, la que se ocupa de estudiar fenómenos empíricamente verificables, sin renunciar a explicar el porqué de las normas (Correas, 1993, p. 28). Pues al final del día, como lo previó Bobbio (1993, en Bidart, 1989, p. 83), el problema de los derechos humanos no consiste en reconocer cuántos y cuáles son todos los derechos, ni preocuparse por su naturaleza y fundamento, sino encontrar la vía más eficaz para garantizarlos.

La eficacia de los derechos humanos está íntimamente ligada no sólo al rol que juegan las instituciones estatales en el ámbito de sus atribuciones, sino también, a una serie de factores sociológicos que inciden en el modo de compenetra- 
ción de estos derechos a la conciencia colectiva de una sociedad (Durkheim, 2007, p. 53). Este concepto de conciencia colectiva de Durkheim es similar a la noción de creencias socialmente compartidas que Weber (2014, pp. 390-391) expuso en sus postulados, pues se refiere a la forma en que los integrantes de una sociedad se identifican uniformemente con una gama de sentimientos y percepciones, que consecuentemente fortalecen sus lazos sociales.

De allí pues, que los estudios sociojurídicos comenzaran a abordar de modo más constante el tema de los derechos humanos. Conforme a Ansolabehere (2010, pp. 28-29), los derechos humanos pueden estudiarse desde dos perspectivas dominantes en el campo de los estudios sociojurídicos: desde su institucionalización, que se centra en el cómo y cuándo los derechos humanos se cristalizan en normas jurídicas, y desde su vivencia, enfocándose en la forma en que las personas, las organizaciones y los movimientos sociales se apropian de las instituciones jurídicas y el impacto que éstas tienen en ellos. Para Bustamante (2017b, p. 47), un enfoque sociológico parte del principio epistemológico de las relaciones sociales como el origen de todo lo social, que incluye a los derechos humanos. Comprendidos los derechos humanos como una forma de empoderamiento en todas las personas para protegerse de las condiciones de vulnerabilidad que emanan de actos de las autoridades estatales -legislativas y ejecutivas.

Para analizar a los derechos humanos desde su vivencia, es puntual recordar lo que Weber (2014, pp. 390-391) comprendía por legitimidad en el derecho. Desde su opinión, ésta se basa en creencias socialmente compartidas. De acuerdo con la interpretación de Bustamante (2017a, p. 44) en torno a los conceptos sociológicos fundamentales de Weber, una creencia es socialmente compartida en la medida en que la comunidad reconoce una expresión o comportamiento con el mismo sentido y significado y por ende se comparte culturalmente. Así mismo, y de acuerdo con Francisco Gil Villegas M. en los comentarios a la obra de Max Weber (2014, p. 104), el significado de legitimidad que el autor aborda es muy distinto al de legalidad que normalmente permea en los estudios jurídicos sobre la forma de legitimación de los Estados, que se asocia principalmente con aspectos legislativos, políticos y judiciales.

Un buen ejercicio para comprender la importancia de las creencias compartidas es el ejemplo que plantean Camino y Mendoza (2004, pp. 87-88). Ellos describen un caso hipotético situado en una villa de la Europa del siglo XIV, en que se cuestionan qué esperarían de la vida dos jóvenes de doce años -uno de los dos, hijo del señor feudal- en términos de sus derechos fundamentales, tomando en cuenta el régimen de aquella época. La reflexión de este ejemplo permite captar la relación existente entre "los derechos, las prácticas culturales y las expectativas personales" (Camino y Mendoza, 2004, p. 88). De tal suerte que para responder a las interrogantes sobre el tipo de vida al que aspiran ambos jóvenes, es necesario recurrir no a creencias individuales, sino a creencias colectivas sobre destinos individuales, es decir, creencias compartidas por los miembros de una comunidad que influyen en la visión del mundo y de la vida (Camino y Mendoza, 2004, pp. 87-88). De manera que estas creencias influirían en las distintas expectativas que ambos jóvenes tendrían de la vida, pues su posición en el régimen y las prácticas culturales de esa época, inciden directamente en su concepción sobre sus derechos fundamentales.

Esto sucede con los derechos humanos si se analizan desde un enfoque sociológico. Pues de acuerdo con el contexto social vigente, la percepción que se tenga de ellos puede variar. De modo que, este enfoque permite interpretar a los derechos humanos como elementos susceptibles de ser integrados a la cultura de un colectivo 
-ya sea de forma positiva o negativa- o bien a la visión de un individuo. El proceso de estas integraciones se da a través del conocimiento sobre sus alcances, así como del grado de información y apropiación de las instituciones y mecanismos de garantía con que cuenta una persona para demandar del Estado sus obligaciones. Por conducto de estas integraciones se produce un efecto empírico de los ordenamientos constitucionales e internacionales, pues de lo contrario las legislaciones sólo serían cuerpos normativos sin vida y no generarían una transformación de la realidad social.

Aunado a lo anterior, otra dimensión sociológica de los derechos humanos se activa cuando su transgresión ocurre por motivos de género, condición social, nacionalidad o situación migratoria. En estos casos, su alcance jurídico pasa a segundo término, pues se han rebasado los campos de estudio del derecho al presentarse implicaciones asociadas a la discriminación, a la xenofobia y algunas veces, a la violencia.

En tal virtud, la perspectiva sociológica no sólo se ocupa de interiorizar en el rol del sujeto de derechos frente a las instituciones, en su capacidad de agencia para denunciar una violación -en caso de ser necesario- o en su grado de asimilación de los derechos humanos, sino que también puede expandir su análisis hacia las causas que originan la discriminación del sujeto o su vulnerabilidad.

Para sintetizar lo expuesto en este apartado se presenta el siguiente cuadro explicativo de los principales enfoques sobre los derechos humanos:

Cuadro 1. Características y debilidades de los principales enfoques sobre los derechos humanos

\begin{tabular}{l|l|l}
\hline Enfoque & \multicolumn{1}{|c|}{ Características principales } & \multicolumn{1}{c}{ Críticas o debilidades } \\
\hline Filosófico & a) Concibe a los derechos & a) Existen países donde no se han \\
humanos como congénitos & reconocido derechos humanos \\
a la persona, es decir, como & universalmente consensados. \\
un conjunto de atributos & b) La articulación sobre sus \\
connaturales a la especie & fundamentos, naturaleza y \\
humana, producto de su & principios no dirime un conflicto \\
dignidad. & sobre violación o irrespeto. \\
& c) El punto central de los \\
& derechos humanos no radica en su \\
& naturaleza o en la dignidad de las \\
& personas, sino en los procesos de \\
& fundamentalización por los que son \\
& regulados y garantizados por los \\
& derechos interno e internacional. \\
& \\
&
\end{tabular}




\begin{tabular}{|c|c|c|}
\hline Sociológico & $\begin{array}{l}\text { a) Los derechos humanos } \\
\text { se deben estudiar desde } \\
\text { su vivencia, es decir, } \\
\text { enfocándose en la forma } \\
\text { en que las personas, } \\
\text { las organizaciones y los } \\
\text { movimientos sociales se } \\
\text { apropian de las instituciones } \\
\text { jurídicas y el impacto que } \\
\text { éstas tienen en ellos. } \\
\text { b) Parte del principio } \\
\text { epistemológico de las } \\
\text { relaciones sociales como } \\
\text { el origen de todo lo social, } \\
\text { que incluye a los derechos } \\
\text { humanos. Entendidos los } \\
\text { derechos humanos como una } \\
\text { forma de empoderamiento } \\
\text { con el objeto de que las } \\
\text { personas contrarresten las } \\
\text { condiciones de vulnerabilidad } \\
\text { que emanan de actos de } \\
\text { las autoridades estatales - } \\
\text { legislativas y ejecutivas-. } \\
\text { c) Permite interpretar a los } \\
\text { derechos humanos como } \\
\text { elementos susceptibles de ser } \\
\text { integrados a la cultura de un } \\
\text { colectivo o bien a la visión } \\
\text { de un individuo. El proceso } \\
\text { de estas integraciones se da a } \\
\text { través del conocimiento sobre } \\
\text { sus alcances y del grado de } \\
\text { información y apropiación de } \\
\text { las instituciones y mecanismos } \\
\text { de garantía con que se cuenta } \\
\text { para reclamar al Estado. }\end{array}$ & $\begin{array}{l}\text { a) Puede omitir la perspectiva de } \\
\text { las instituciones gubernamentales, } \\
\text { que son actores clave en el tema de } \\
\text { los derechos humanos, al enfocarse } \\
\text { abiertamente en el sujeto titular de } \\
\text { las prerrogativas. } \\
\text { b) Existen sesgos metodológicos } \\
\text { en la búsqueda y obtención de la } \\
\text { información, pues hay pocas fuentes } \\
\text { de información fidedignas que den } \\
\text { cuenta de la percepción de los } \\
\text { sujetos titulares. Por lo que exige la } \\
\text { construcción de un instrumento de } \\
\text { recolección de datos }\end{array}$ \\
\hline
\end{tabular}




\begin{tabular}{l|l|l}
\hline Jurídico-político & a) Se basa en el proceso de & a) La evidencia histórica ha \\
& fundamentalización de los & comprobado que los derechos \\
derechos humanos. Este & institucionalizados no \\
puede darse a través de & necesariamente guardan correlación \\
dos ejercicios soberanos: & con el goce y disfrute de ellos. \\
el constitucional y el & b) La firma de un tratado \\
internacional. & internacional no produce en \\
& automático mejoras en la protección \\
& de derechos humanos, salvo que \\
& la verdadera pretensión sea ésta y \\
& no fortalecer vínculos comerciales, \\
& relaciones interestatales, o presentar \\
& un rostro afable a la comunidad \\
& internacional. \\
& c) Los procesos de \\
& fundamentalización de los \\
& derechos humanos a través de \\
& fuentes de carácter internacional \\
& corren el riesgo de convertirse en \\
& instrumentos manejables por los \\
& Estados, quienes podrían enfocarse \\
& en intereses políticos y económicos y \\
& no de protección. \\
\hline
\end{tabular}

Fuente: Elaboración propia.

\section{VENTAJAS METODOLÓGICAS DEL ENFOQUE SOCIOLÓGICO DE LOS DERECHOS HUMANOS}

Los derechos humanos como concepto filosófico al ser integrados a las relaciones sociales $\mathrm{o}$, al salir de los instrumentos legislativos, nacionales e internacionales, se transforman en elementos susceptibles de apropiación por los sujetos titulares. Esta apropiación puede presentarse a manera de información, de reconocimiento o incluso de lucha o movilización social. Cuando los derechos humanos son apropiados por las personas o grupos, mutan en instrumentos capaces de ser utilizados en los momentos oportunos, sea cuando se reconozca una trasgresión, sea cuando se exija una obligación del Estado.

Esta instrumentación de los derechos humanos a cargo de las personas o grupos genera un aumento en su capacidad de agencia y por ende convierte a los derechos humanos en una forma de empoderamiento frente a las posibles violaciones que pueda ejecutar el Estado a través de sus diferentes encarnaciones institucionales. Con base en esto, al ser adoptados por los sujetos titulares pueden ser utilizados como medios de defensa frente a diversas situaciones que pongan en peligro el goce de estas prerrogativas o que los coloquen en situaciones de vulnerabilidad, activando socialmente los derechos humanos.

Una de las varias razones comunes por las que se presentan violaciones a derechos humanos en las sociedades contemporáneas es el desconocimiento de 
estos. García Ramírez (2014) ha hablado de esto cuando se refiere a los puentes por los que se conectan los órdenes jurídicos interno e internacional que son cinco: el constitucional, el legal, el político, el jurisdiccional y el cultural. El puente cultural consiste en la recepción o acogimiento de los derechos humanos en la cultura de un país, ya que en la magnitud de esta recepción social estriba su tutela, pues conlleva a una mayor exigencia de cumplimiento por parte de la comunidad; estos aspectos culturales solamente pueden ser identificados por conducto de un enfoque sociológico que observe estos márgenes de recepción o acogimiento en los sujetos titulares y no privilegie el rol de las instituciones gubernamentales o de las legislaciones.

Una primera ventaja metodológica del enfoque sociológico de los derechos humanos es que permite conocer directamente de los sujetos titulares, su sentir acerca de la situación pragmática para el ejercicio de sus derechos, pues cuando se observa la información desde las autoridades del Estado, es probable que la verdad se diluya en la frialdad de las estadísticas, de los números o de la racionalidad institucional. Haber focalizado las investigaciones en materia de derechos humanos en una postura estado-céntrica, ha generado enormes compendios de análisis legislativo y de funciones estatales, pero la situación en la realidad social de estas prerrogativas es igual e incluso se ha tornado más crítica.

Lo anterior obedece a que, por alguna extraña razón, el análisis de los derechos humanos se ha distanciado del análisis de los propios humanos como titulares de tales prerrogativas. En otras palabras, un enfoque sociológico de los derechos humanos no sólo les confiere voz a los sujetos titulares de estas prerrogativas, sino que también vuelve factible estimar los grados de efectividad de las vías legales con que cuentan y conocer los factores que inciden en que estos mecanismos sean o no empleados, como se explicará en la siguiente ventaja.

Una segunda ventaja metodológica estriba en que, al recabar la información de los grados de apropiación de las personas o grupos en torno a los derechos humanos, se estará en una mejor posición para efectuar una valoración de la efectividad de los instrumentos jurídicos existentes. Los grandes compendios de análisis legislativo que se han construido desde las Ciencias Jurídicas serían de más provecho en la medida en que, estos pudieran ser cotejados con la percepción de los sujetos titulares en relación con las prerrogativas estudiadas.

Estos cotejos sólo son posibles a través de la aplicación de un enfoque sociológico que recolecte previamente los datos de los sujetos titulares y después proceda a la evaluación de los mecanismos jurídicos, a partir de su comparación con la información interpretada de los sujetos de derechos humanos, con la finalidad de establecer la asociación o disociación entre la institucionalización de los derechos humanos y la forma en que se viven en la realidad social. Este análisis permite inferir si los derechos humanos han sobrepasado la barrera jurídica para convertirse en instrumentos susceptibles de ser apropiados por los actores sociales, o, en otras palabras, se ha construido firmemente el puente cultural que conecta a los órdenes jurídicos con la comunidad.

Una tercera ventaja metodológica es que a través de este enfoque sociológico se pueden identificar problemas, reconfigurar conceptos y ratificar elementos teóricos. Existe el gran riesgo que a partir de los otros dos enfoques analíticos de los derechos humanos se produzcan resultados repetitivos y pocas veces se construyan críticas hacia conceptos o elementos teóricos, hasta ese momento, reconocidos como válidos, ello sucede porque no se ponen en comparación los contenidos teóricos con los aspectos de la realidad social que pueden emerger de un enfoque 
sociológico; al mismo tiempo, se pueden ratificar, comprobar y robustecer conocimientos conceptuales preexistentes.

El gran problema con la aplicación metodológica de este enfoque es que las fuentes de información existentes (censos, encuestas, informes, trabajos académicos) sobre el estudio de los derechos humanos, enfatizan en los mecanismos de protección (organismos protectores, marcos normativos, etc.) y sus grados de aplicabilidad. Dejando de lado la intervención del sujeto titular en los procesos de información, apropiación y exigencia de los derechos humanos. Por lo tanto, estas fuentes de información pueden ser utilizadas únicamente para efectos ilustrativos y contextuales.

Por consiguiente, se torna menester la formulación y diseño de instrumentos de recolección de datos que facilite la obtención de la percepción en materia de derechos humanos de los sujetos titulares. Este instrumento puede realizarse a través de una entrevista semiestructurada (pero también a partir de otras técnicas y herramientas metodológicas) aplicada a las diferentes poblaciones objetivo y por medio de un análisis cualitativo de la información recabada durante el trabajo de campo.

\section{CONCLUSIONES}

Existen diferentes enfoques para analizar a los derechos humanos, principalmente desde las disciplinas jurídicas y sociales, sin embargo, han sido las primeras las que han sostenido el dominio y hegemonía de su estudio. El interés de otras Ciencias Sociales distintas a la Filosofía por abordar los derechos humanos y responder interrogantes acerca de diversos fenómenos sociales, políticos y culturales fue construyendo enfoques paralelos al jurídico que abonarían a un progreso multidisciplinario de este tópico.

La marcada postura estado-céntrica que impera en los estudios de corte jurídico acerca de los derechos humanos, produjo una falta de convencimiento de que a partir de tales avances teóricos se podían resolver las inquietudes emanadas de las Ciencias Sociales. Esta postura estado-céntrica que privilegia el rol del Estado a través de sus instituciones y los marcos legislativos internos e internacionales, se había distanciado del elemento central de los derechos humanos: la persona, el sujeto titular.

Por consiguiente, comenzó a tomar repercusión un enfoque sociológico, que se interesaba más por el sujeto titular que por el sujeto obligado, en el binomio Estado-Individuo que existe en materia de derechos humanos. No obstante, la sustitución de la persona por el Estado en cuanto al sujeto protagónico en el análisis de los derechos humanos no sería propiamente el aspecto central en esta modificación de enfoques, sino que ahora había una mayor ocupación de la manera en que estas prerrogativas se insertan en la realidad social, en el mundo de las relaciones sociales.

Un enfoque sociológico no solamente facilita el otorgamiento de voz a los sujetos titulares de los derechos humanos, para conocer la realidad de estos en un plano social, sino además permite la evaluación de los mecanismos jurídicos existentes, su pertinencia, efectividad y la necesidad de reconfigurar figuras legales o institucionales. Así mismo, abre el camino para la valoración de algunos presupuestos teóricos hasta entonces validados o incluso, a la construcción de nuevas aportaciones teórico-conceptuales que sumen a las interrogantes contemporáneas en torno a los derechos humanos. 
Como todo enfoque analítico, el enfoque sociológico cuenta con algunas debilidades metodológicas, principalmente relacionadas con la ausencia de fuentes de información (censos, encuestas, informes, trabajos académicos) que puedan ser empleadas en las investigaciones asociadas a los derechos humanos. Empero, esta debilidad no es insubsanable, ya que, a través de un debido diseño, se puede construir un sólido instrumento de recolección de datos, que después pueda ser interpretado a través de un análisis cualitativo de la información. Así mismo este instrumento de recolección de datos puede asumir las particularidades necesarias tomando en consideración la población objetivo y el tipo de derecho humano que se esté analizando.

Hoy vivimos una época crítica en materia de derechos humanos, la postura estado-céntrica para el análisis de estos temas no ha sido suficiente para proponer, resolver o en todo caso, identificar los aspectos torales de las violaciones a estos derechos. Hay países que, aunque son líderes en la suscripción de acuerdos internacionales, son quizá quienes más ejecutan trasgresiones a derechos humanos todos los días. Este escenario permite inferir que los enfoques filosófico y jurídico-político no han dado respuesta a estas inquietudes que seguramente van más allá de las instituciones y los marcos legislativos con base en los que ellas operan.

No se quiere con esta afirmación, eliminar el progreso teórico que se ha obtenido de los dos enfoques mencionados, que se ve vislumbrado en la integración de los derechos humanos a las principales políticas públicas del mundo, a las Constituciones, leyes y acuerdos jurídicos en todas las geografías, y a la inclusión que han tenido en las instituciones educativas. Pero el apartado teórico no está resuelto, hoy existen nuevas interrogantes: ¿Universalidad o Interculturalidad? ¿Congénitos, deliberativos o producto de luchas sociales? Son preguntas que no han podido contestarse con los enfoques hegemónicos.

Se estima que con la reproducción del enfoque sociológico se esté en condiciones de proponer otras respuestas, nuevas aportaciones teóricas e incluso inesperadas interrogantes que hasta hoy no se han planteado y que no se plantearán mientras el enfoque detrás de todas las perspectivas analíticas siga siendo el mismo: la postura estado-céntrica. El enfoque sociológico pretende retornar a las bases, aprovechándose de los avances hasta ahora conseguidos, unas bases que tal vez, nunca debieron de haberse diluido, que no son otra cuestión, sino el reconocimiento de que el eje central de los derechos humanos es la persona como sujeto titular y no el Estado como sujeto obligado.

\section{REFERENCIAS}

1. Ansolabehere, K. (2010). Los derechos humanos en los estudios sociojurídicos. En Estévez, Ariadna, y Vázquez, Daniel (coords.). Los derechos humanos en las ciencias sociales: una perspectiva multidisciplinaria. México: Flacso México/Universidad Nacional Autónoma de México, Centro de Investigaciones sobre América del Norte, pp. 19-41.

2. Arias Marín, A. (2015). Tesis sobre una teoría crítica de los Derechos Humanos, Open Insight, VI, (9), enero-junio 2015, pp. 11-33. 
3. Bidart Campos, G. J. (1989). Teoría general de los derechos humanos. México: Universidad Autónoma de México/Instituto de investigaciones Jurídicas.

4. Bustamante, J. (2017a), Max Weber Revisited, the Verstehen of migration through Qualitative research. Migraciones internacionales, 9(1), pp. 43-67.

5. Bustamante, J. (2017b). Mexican Immigration to the United States, the vulnerability-resilience of migrants and their circularity. University of Notre Dame and El Colegio de la Frontera Norte -submitted for publication in "The American Journal of Sociology".

6. Camino, L. y R. Mendoza (2004). La construcción de los derechos humanos y la necesidad de la psicología política. Psicología Política, (28), pp. 85-103.

7. Carpizo, J. (2011). Los derechos humanos: naturaleza, denominación y características. Cuestiones constitucionales, Revista Mexicana de Derecho Constitucional, (25), julio-diciembre 2011, pp. 3-29.

8. Carpizo, J. (2012). La Constitución mexicana y el derecho internacional de los derechos humanos. Anuario Mexicano de Derecho Internacional, (XII), 2012, pp. 801-858.

9. Centro Latinoamericano y Caribeño de Demografía (CELADE) y División de Población de la Cepal (2010). Impacto de la crisis económica en la migración y el desarrollo: Respuestas de política y programas en Iberoamérica. El Salvador, CEPAL/OIM/Secretaría General Iberoamericana/República de El Salvador en la América Central.

10. Correas, Ó. (1993). La sociología jurídica. Un ensayo de definición. Crítica Jurídica. Revista Latinoamericana de Política, Filosofía y Derecho, (12), pp. 23-53.

11. Declaración Universal de los Derechos Humanos (1948). Recuperado de http://www.un.org/es/universal-declaration-human-rights/.

12. Durkheim, E. (2007). La división del trabajo social. México: Colofón.

13. Estévez, A. (2017). El discurso de derechos humanos como gramática en disputa. Discurso y Sociedad, 11(3), pp. 365-386.

14. Flores-ivich, G. y R. Salazar-Elena (2014). Institucionalización y disfrute de derechos humanos en América Latina. En Ansolabehere, Valdés Ugalde y Vázquez (eds.). Entre el pesimismo y la esperanza: los derechos humanos en América Latina. Metodología para su estudio y medición. México: FLACSO, pp. 159-180.

15. García, L. (2016). Migraciones, Estado y una política del derecho humano a migrar: ¿hacia una nueva era en América Latina? Revista Colombia Internacional, (88), pp. 107-133. 
16. García Ramírez, S. (2008). Cuestiones de la jurisdicción interamericana de derechos humanos, Anuario Mexicano de Derecho Internacional, (VIII), pp. 187-221.

17. García Ramírez, S. (2014). Recepción nacional del derecho interamericano de los derechos humanos. Implicaciones penales. En García Ramírez, S., González, O. y Peláez, M. (coords.). Criterios y jurisprudencia interamericana de derechos humanos: influencia y repercusión en la justicia penal. México: Universidad Nacional Autónoma de México/Instituto de Formación Profesional de la Procuraduría General de Justicia del Distrito Federal.

18. Heyns, Christof, Padilla, David y L. Zwaak (2006). Comparación esquemática de los sistemas regionales de derechos humanos: una actualización. African Human Rights Law Journal, (5) pp. 308-320.

19. Organización de las Naciones Unidas (ONU) (1948). Declaración Universal de los Derechos Humanos. Recuperado de http://www.un.org/es/ universal-declaration-human-rights/.

20. Rubalcava, R. M. (2014). La construcción de medidas de derechos humanos: una tarea interdisciplinaria. En Ansolabehere, Valdés Ugalde y Vázquez (eds.). Entre el pesimismo y la esperanza: los derechos humanos en América Latina. Metodología para su estudio y medición. México: Flacso México, pp. 41-54.

21. Velásquez Monsalve, J. D. (2013). El derecho natural en la Declaración Universal de los Derechos Humanos. Revista Facultad de Derecho y Ciencias Políticas, 43 (119), pp. 735-772.

22. Weber, M. (2014). Economía y sociedad. México: Fondo de Cultura Económica. 